\author{
Military Technical College \\ Kobry Elkobbah, Cairo, \\ Egypt.
}

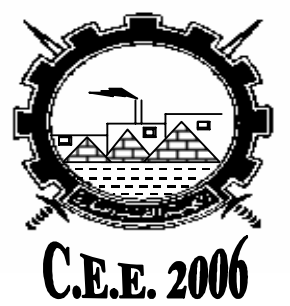

$3^{\text {rd }}$ International Conference

On

Chemical \& Environmental

Engineering

\title{
TEXTILE FABRIC TREATMENT AGAINST RADAR DETECTION USING CARBON BLACK
}

\author{
Fayed M. Sh. *, Allam A. M. * and Mostafa Sh. F. *
}

\begin{abstract}
The reduction of radar signature for textile fabric by treating with carbon black powder dissolved in shellac solution (shellac dissolved in ethanol) is investigated. In this study, carbon black was added with known concentration in shellac solution and mixed until solution formula was homogenous. Also, the textile fabrics were chosen from the commercially available ones with known specifications and characterizations. All of them were obtained before dyeing and without any further treatment and they were prepared with known dimensions. Another different polymeric compound was used with carbon black which was commercial epoxy resin. The prepared textile fabric was treated with the solution of carbon black and dissolved shellac by impregnation of the textile sample or by coating in case of using carbon black mixed with epoxy resin. After treatment of textile fabric with the chemical solution containing carbon black, the obtained textile sample was tested by microwave reflectometer to measure the reduction in reflected radar power and so the reduction of radar signature. The results of these measurements were recorded.
\end{abstract}

\section{KEY WORDS}

Radar signature; textile fabric; carbon black; shellac solution; microwave reflectometer; reflected radar power.

\footnotetext{
* Egyptian Armed Forces.
} 


\section{INTRODUCTION}

Stealth is the art of concealing targets from detectors by reduction of signature. The threat of radar detection is usually a major concern to an attacking force and a lot of effort was put into trying to reduce radar signature [1]. The stealth technologies aim to the design and proposal of materials and techniques that can lead to the reduction of the target signature are the infrared, visible, acoustic and radar domains [2]. Radar cross section(RCS) is a measure of reflective strength of target. Also it is defined as the projected area of a metal sphere which would return the same echo signal as the target had the sphere been substituted for the target[3-5]. The methods of radar cross section reduction are shaping, radar absorbing materials, passive cancellation and active cancellation. Although shaping has an important role in radar cross section reduction(RCSR) and can provide reduction in signature over limited aspect angles, many situations require absorption of the incident electromagnetic energy. Radar absorbing materials are based on the fact that some substances absorb energy from electromagnetic field passing through them $[5,6]$. The material ability to store energy was characterized by defining two parameters, permittivity $(\epsilon)$ that characterizes materials ability to store electrical energy and permeability $(\mu)$ that characterizes materials ability to store magnetic energy. The loss refers to the dispersion of power or energy [7]. The radar absorber measurement techniques are RCS method, the naval research laboratory (NRL) arch method and large waveguide system [8-10].In this research work, we concentrated on applying the technique of radar absorbing material as one of the simplest ways to reduce the returned radar signal power from the object. We have selected carbon black since it is used with loaded foam pyramid absorbers applied in anechoic chambers [11]. The reduction of radar signature for textile fabric selected with known characteristics was done by treatment of the textile fabric with carbon black dissolved in shellac solution (shellac dissolved in ethanol) with known concentration by immersing the textile sample in the emulsion formula of carbon black until saturation. This was repeated several times until constant weight of the sample. The drying process was done in oven. The treated sample was also tested as radar absorbent by using microwave reflectometer to measure the reduction in reflected radar power. This device containing of two horns transmitter and receiver. The electro magnetic wave was transferred from transmitter and reaches the fixed sample and returned to receiver with certain value. The microwave reflectometer measure the loss or reduction in the reflected radar power. The obtained values were recorded along the frequency band 8-18 GHz.

\section{EXPERIMENTAL WORK}

\subsection{Experimental Set-up}

The PR-17 microwave reflectometer is portable, swept frequency reflectance analyzer used for the testing of the microwave reflectivity of surface. It operates in free space using transmit and receive antennas oriented at a \pm 15 degree bistatic angle compared with the surface normal to measure relative return loss.

The reflectometer gun as shown in figure (1) contains internal computer to control system operations and displays and stores the measured data. Also the transmit and receive antennas which send and receive the electromagnetic wave and record the reduction in reflected radar power. 


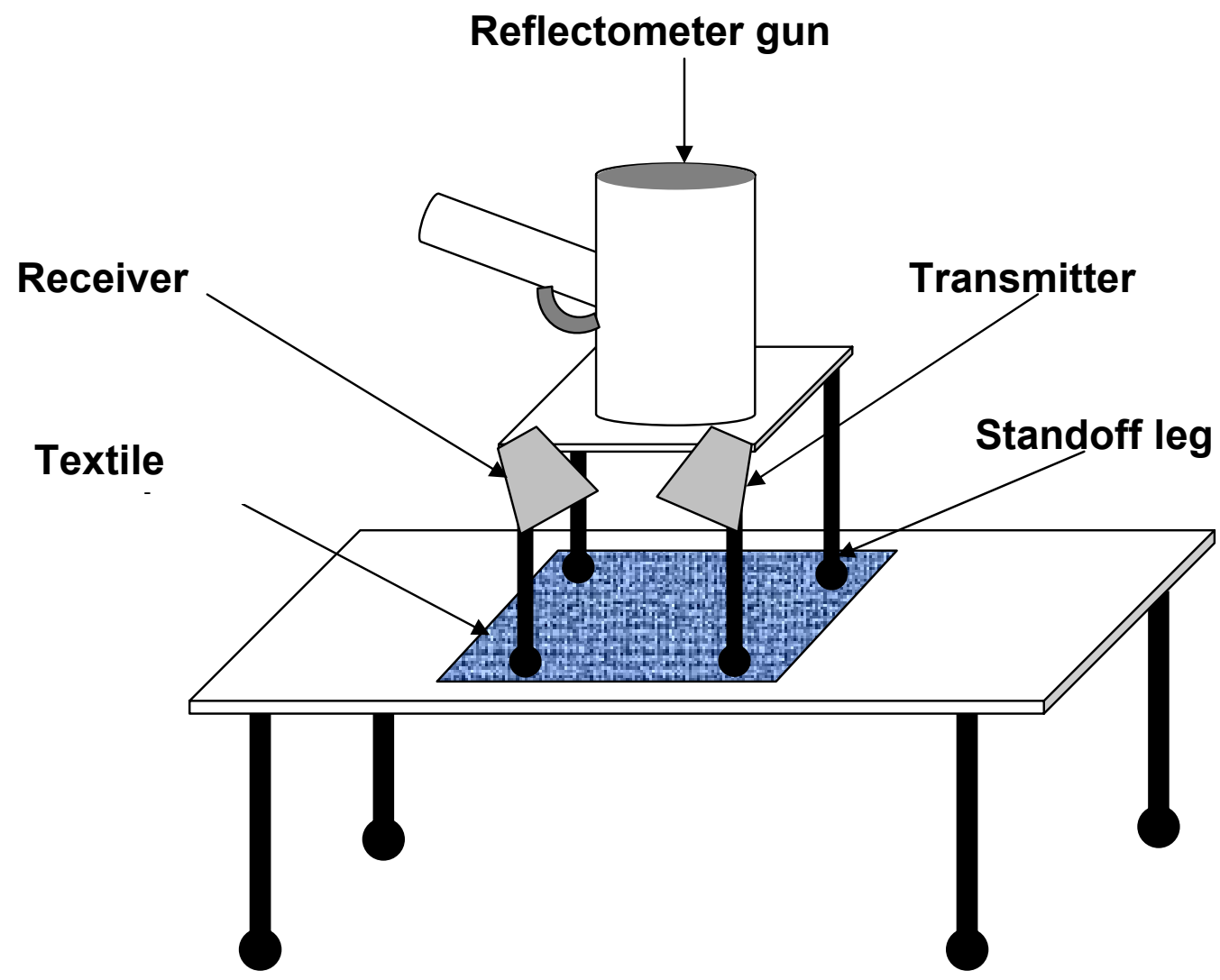

Fig. 1. Experimental set-up of testing textile sample by microwave reflectometer

\subsection{Textile Fabric Specifications}

The textile fabrics were chosen from the commercially available ones with known specifications and characterization. All these textile fabrics were obtained before dyeing and without any further treatment. The selected samples of different types were cut into specimens of known dimensions $30 \times 30 \mathrm{~cm}^{2}$, which is the suitable size for testing. The specimens were weighed before treatment and testing. The type of textile fabrics used was cotton $100 \%$ ( plain weave) and mixed(cotton $40 \%$ and polyester $60 \%$ ) of satin weave. 
Table 1. Textile fabric specifications

\begin{tabular}{|c|c|c|c|c|c|c|c|c|}
\hline \multirow{3}{*}{ No. } & \multicolumn{8}{|c|}{ Fabric type } \\
\hline & \multirow{2}{*}{ Structure } & \multirow{2}{*}{ Raw material } & \multirow{2}{*}{$\begin{array}{l}\text { Weight } \\
\left(\mathrm{gm} / \mathrm{m}^{2}\right)\end{array}$} & \multirow{2}{*}{ Count } & \multirow{2}{*}{ No./cm } & \multirow{2}{*}{$\begin{array}{l}\text { Thickness } \\
(\mathrm{mm})\end{array}$} & \multicolumn{2}{|c|}{ Strength $(\mathrm{kg})$} \\
\hline & & & & & & & Width & Length \\
\hline 1 & $\begin{array}{c}\text { Plain } \\
\text { weave } \\
\text { (Gercie) }\end{array}$ & $100 \%$ Cotton & 240 & $24 / 1$ & $9 \times 16$ & 0.96 & 40.6 & 21.7 \\
\hline 2 & $\begin{array}{l}\text { Satin } \\
\text { weave } \\
\text { (Rib) }\end{array}$ & $\begin{array}{c}\text { Mixed (Cotton } \\
40 \% \text {,Polyester } \\
60 \% \text { ) }\end{array}$ & 270 & 20/1 & $10 \times 17$ & 0.94 & 40.9 & 23.1 \\
\hline
\end{tabular}

Where:

Count: number of fibrles per one inch.

Weight: weight of sample per meter square.

No. /cm: number of fibrles per $\mathrm{cm}$ in both width and length directions.

\subsection{Preparation Of Chemical Solution}

\section{A) In shellac alcoholic solution:}

The mentioned natural polymer $(100 \mathrm{gm})$ was dissolved in pure ethanol $(500 \mathrm{ml})$ and thoroughly mixed until complete dissolution of shellac to form a dark brown true solution, then $200 \mathrm{gm}$ of this prepared solution was weighed and then carbon black $(20,30,40$ and $50 \mathrm{gm})$ was separately added to the prepared solution and thoroughly mixed. The solution was saturated after adding $50 \mathrm{gm}$ of carbon black so that the last sample was treated with solution containing this amount of carbon black. The textile samples were soaked in this solution for $5 \mathrm{~min}$, dried and weighed. This is repeated several times until constant weight of the sample. The drying process was done in oven at $50^{\circ} \mathrm{C}$ for 3 hours. The treated samples were also tested as radar absorbent. The steps of soaking process were as follows:

1) Immerse the fabric sample in the emulsion of each formula for $15 \mathrm{~min}$. at room temperature.

2) Squeeze the sample between two filter papers and run a roller of certain weight on the sample several times.

3) Dry the sample at the oven at $50^{\circ} \mathrm{C}$ for 3 hours and then weight the sample.

4) Repeat immersion of the sample in the solution and drying, then weight until the weight is constant.

5) Note the variation in weight and record the difference.

\section{B) In commercial epoxy resin:}

The ratio of the resin to hardener is 5:1. The carbon black amount is added to the thoroughly mixed epoxy resin $(200 \mathrm{gm})$ and mixed until saturation. Four samples were prepared with different amount of carbon black $20,30,40$ and $50 \mathrm{gm}$. The mixture is totally used to coat the sample. The solution was saturated after adding $50 \mathrm{gm}$ of carbon black so that the last sample was treated with solution containing this amount of carbon black. The thickness and weight of the coated samples were measured after curing in oven at $50{ }^{\circ} \mathrm{C}$ for 3 hours. The treated samples were then tested as radar absorbent. 
The factors affecting the reduction of radar signature were: effect of concentration of chemical compound in solution formula, Effect of varying wavelength along the frequency band and effect of textile fabric type.

\section{RESULTS AND DISCUSSIONS}

After treatment of textile fabric with a formulation containing variable percentage of carbon black, the results of measurements were illustrated in table 2.

Table 2. Reflected power of $100 \%$ cotton textile fabric treated with different concentration of carbon black in shellac dissolved in ethanol.

\begin{tabular}{|c|c|c|c|c|c|}
\hline \multirow{2}{*}{\multicolumn{2}{|c|}{$\begin{array}{c}\text { Sample Code } \\
\text { Fabric Type }\end{array}$}} & C1 & $\mathrm{C} 2$ & C3 & $\mathrm{C} 4$ \\
\hline & & \multicolumn{4}{|c|}{ Cotton $100 \%$ plain weave } \\
\hline \multicolumn{2}{|c|}{$\begin{array}{l}\text { Sample weight } \\
(\mathrm{gm} / \mathrm{m} 2)\end{array}$} & 410 & 435 & 455 & 470 \\
\hline \multicolumn{2}{|c|}{$\begin{array}{c}\text { Concentration } \\
(\%)\end{array}$} & $9 \%$ & $13 \%$ & $17 \%$ & $20 \%$ \\
\hline \multicolumn{2}{|c|}{$\begin{array}{l}\text { Sample thickness } \\
(\mathrm{mm})\end{array}$} & 0.98 & 1.01 & 1.02 & 1.04 \\
\hline \multicolumn{6}{|c|}{ Reduction in RCS at frequency band $8-18 \mathrm{GHz}(\mathrm{dB})$} \\
\hline \multirow{11}{*}{ 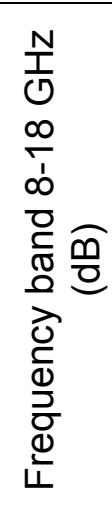 } & 8 & -2.1825 & -3.2817 & -5.1274 & -6.2427 \\
\hline & 9 & -2.7523 & -3.6192 & -5.5319 & -6.7351 \\
\hline & 10 & -3.0127 & -3.9142 & -5.9146 & -7.2274 \\
\hline & 11 & -3.8219 & -4.1358 & -6.1288 & -7.7980 \\
\hline & 12 & -4.1214 & -4.4181 & -6.6315 & -8.1422 \\
\hline & 13 & -4.7291 & -4.8231 & -6.9224 & -8.9652 \\
\hline & 14 & -5.0131 & -5.1281 & -7.1314 & -10.0375 \\
\hline & 15 & -5.5941 & -5.6223 & -7.5124 & -10.5224 \\
\hline & 16 & -5.9281 & -6.0116 & -7.8219 & -10.7997 \\
\hline & 17 & -6.1123 & -6.3288 & -8.0613 & -11.1949 \\
\hline & 18 & -6.3215 & -6.6143 & -8.3215 & -10.7997 \\
\hline
\end{tabular}

The results indicate that the reduction in RCS of the treated textile fabric increases with the increase in the concentration of carbon black in the treating solution (shellac dissolved in ethanol).At each radar wavelength the reduction increase with the percentage of carbon black. Such reduction increases with the increase in the wavelength. The carbon black at high concentration seems to form a barrier coating which impedes diffusion of further carbon black particles into the interior of the fabric. 


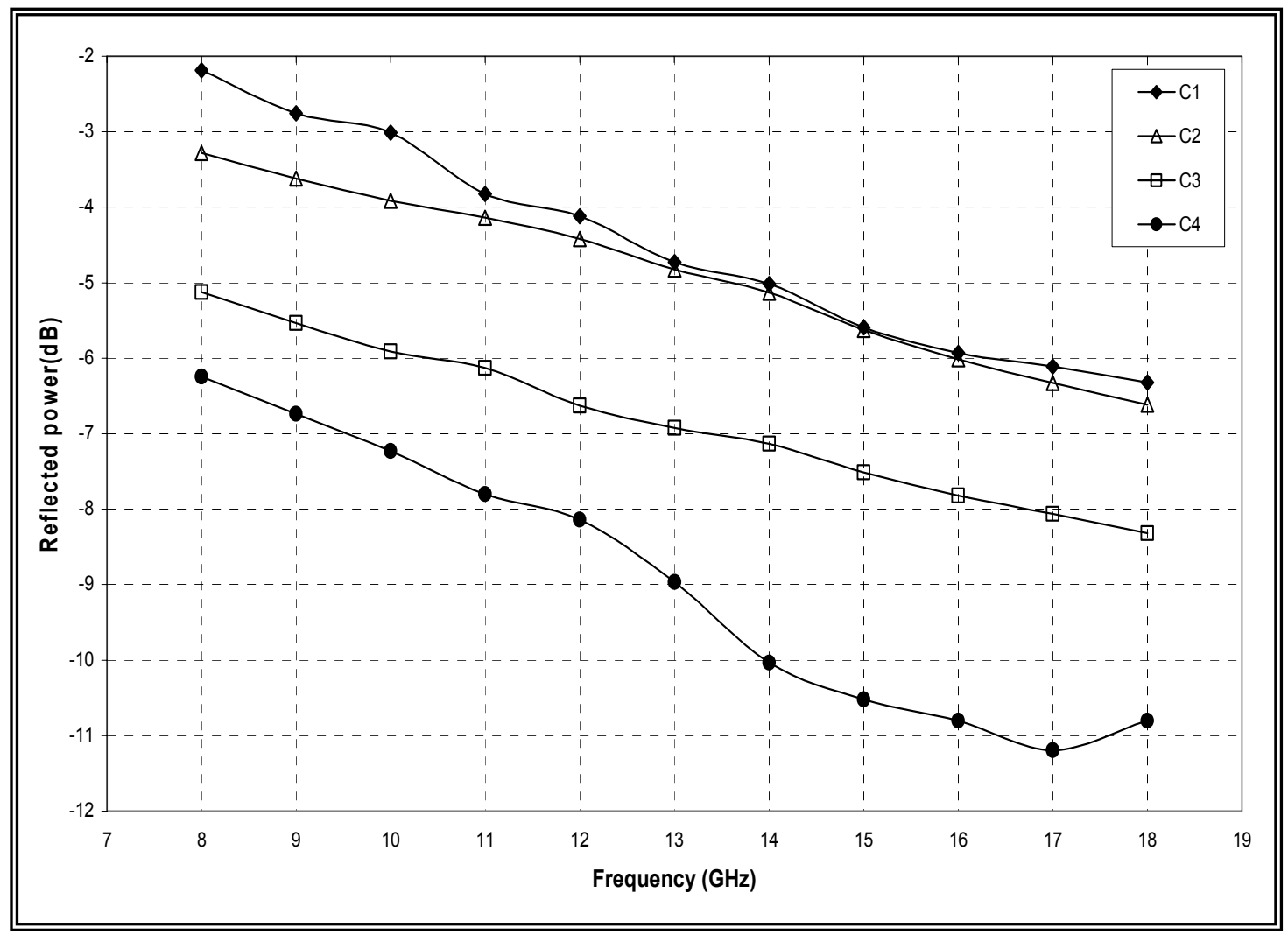

Fig. 2. Relation between the frequency and reflected power of $100 \%$ cotton textile fabric and different concentration of carbon black in alcoholic shellac solution.

Fig.2. illustrates that, for treated samples $(\mathrm{C} 1, \mathrm{C} 2, \mathrm{C} 3$ and $\mathrm{C} 4)$ the reduction in RCS increases as the wavelength increases. Based on these results, the maximum decrease in the radar reflected power was noticed at $17 \mathrm{GHz}$, which is represented in test number 4 for sample $\mathrm{C} 4$. At each sample, the reduction increases with the increase in the wavelength. For sample $\mathrm{C} 1$, as example the reduction at wavelength $17 \mathrm{GHz}$ is about 3 times more than that occurred at wavelength $8 \mathrm{GHz}$.

\subsection{Effect of polymer binder (epoxy binder) on reduction of reflected radar power}

After treatment of $100 \%$ cotton textile fabric with different concentrations of carbon black in commercially available epoxy polymer, the results of measurements were illustrated in fig. 3. 


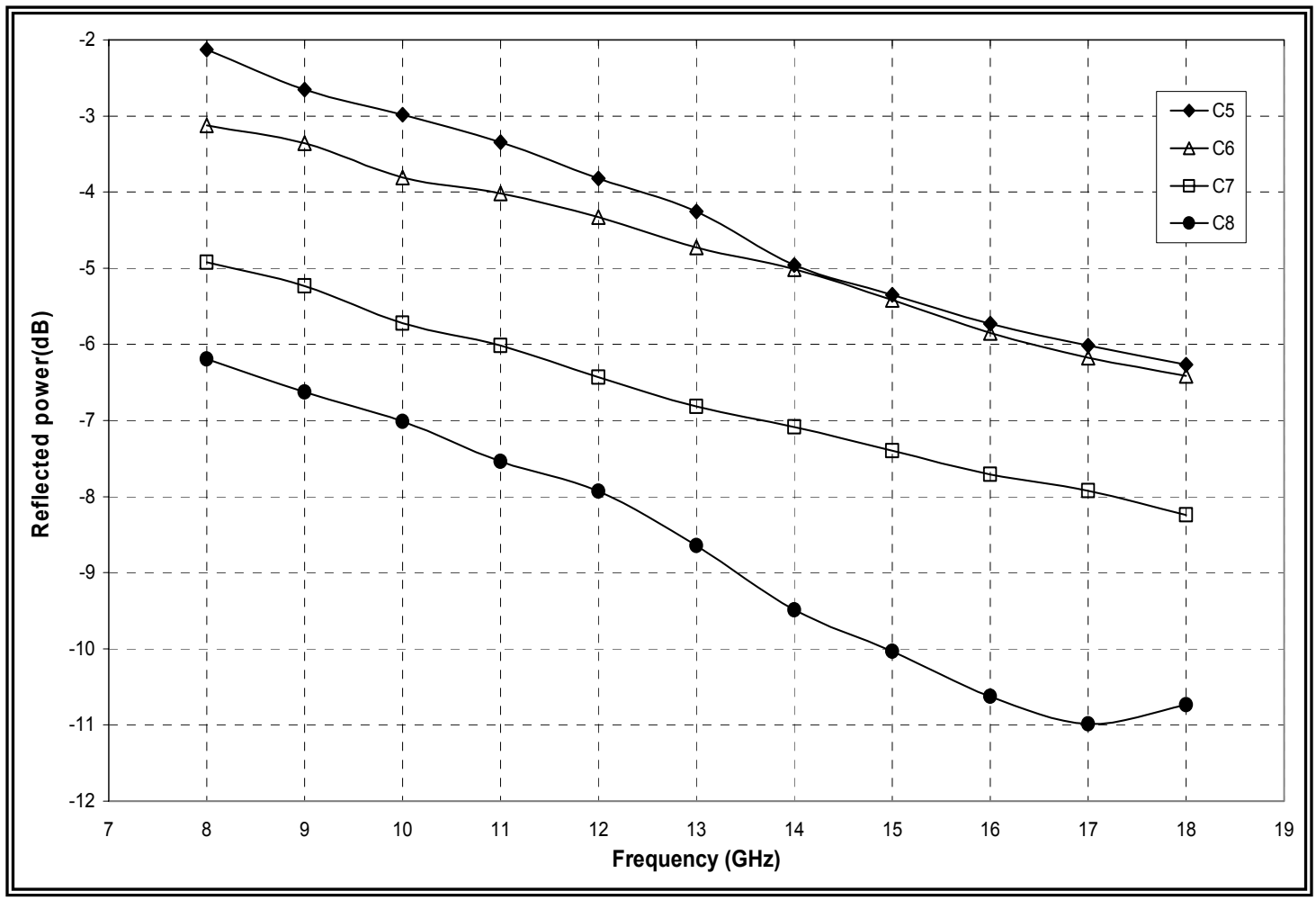

Fig.3. Relation between the reflected radar power of $100 \%$ cotton textile fabric and different concentration of carbon black in epoxy polymer

As shown in fig.3.,we found that there is no great variation in results when changing the type of polymer from the natural shellac to synthetic epoxy polymer. We found that the obtained reduction in radar power is not appreciable, thus the reduction in RCS increased as the carbon black concentration increased. Based on these results, the highest concentration could be prepared in these samples had been determined when using epoxy polymer as adhesive polymer was represented for sample C8 which is approximately similar to that results obtained with shellac dissolved in ethanol. Fig.3. illustrates that, for every curve of tested samples (C5, C6, C7 or C8) the reduction in RCS increases as the frequency increases, but there is a remarkable change in the use of shellac in the mechanical properties which gave a more flexible sample. In the same time, the dissolution of shellac in alcohol makes this solution applicable for the treatment with soaking, while epoxy was applied by coating.

\subsection{Effect of fabric type on reduction of reflected radar power}

Two types of textile fabrics were tested .The above mentioned with cellulosic natural cotton (100\%) to be compared the presented was a blend of cellulosic natural cotton $(40 \%)$ and synthetic polyester $(60 \%)$. The results of measurement were illustrated in fig.4.The fabric weight and fabric structure of the tested samples had an effect on the quantity of absorbed carbon black through the surface of the used fabric, so that the 
fabric type and structure that had been used for treatment were choosed especially for this work.

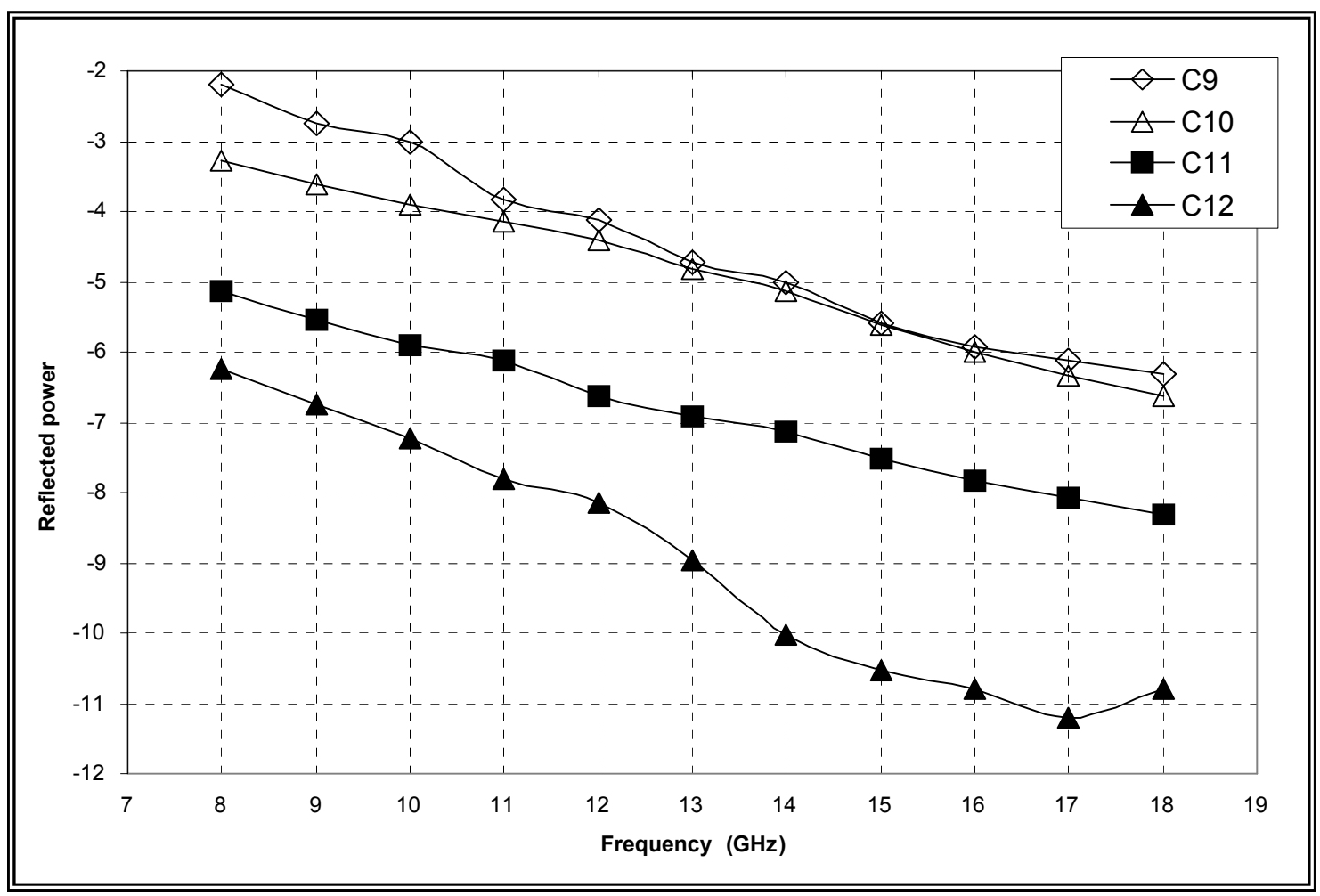

Fig.4. Relation between the reflected radar power of cotton-polyester(40\%-60\%) textile fabric and different concentration of carbon black in shellac dissolved in ethanol.

The results indicated that there is no change in results when we used mixed cotton $40 \%$ and polyester $60 \%$, but when we use textile fabrics with low fabric weight and small thickness for yarn count, the quality of absorbed carbon black through the surface of the used fabric decreased. Generally, we found that as concentration of carbon black in shellac dissolved in ethanol increased the reduction in RCS increased as in for sample C12.

\section{CONCLUSION}

The most commonly used material in field applications is carbon black since it is nonmetallic and non-conducting material so it was selected to be tested for such purpose to study its ef fect and the different factors that can influence such purpose. It is also well known that each radar absorbing material absorbs certain radar wavelength better than the others. Therefore, the aim of such work is also to determine the suitable absorbers wavelengths and so for the proposed field applications. From the experimental work done and the tested samples, it was found that The textile fabrics were chosen to be $100 \%$ cotton and mixed cotton( $40 \%)$ and polyester $(60 \%)$. The 
method of treatment were soaking of mixtures in shellac polymer or coating of textile fabric in case of using commercial epoxy resin. As the concentration of the chemical compound in solution formula increases, the reduction in reflected radar power increases. The sample C4 with $100 \%$ cotton textile fabric treated with shellac dissolved in ethanol and C8 with $100 \%$ cotton textile fabric treated with commercial epoxy resin were better in the range $14-18 \mathrm{GHz}$. The same was also obtained with blend textile fabric cotton(40\%) and polyester (60\%). The reduction in radar power was in the range of $-10.027 \mathrm{~dB}$ to $-11.194 \mathrm{~dB}$.

The textile samples have less thickness and they were more flexible and can be used in different applications like manufacture of tents and covers of army vehicles or can be used to camouflage the fixed objects.

\section{REFERENCES}

[1] W.F.Bahret, "The Beginning of Stealth Technology", IEEE Trans. Aerospace Electron system, USA, 1998.

[2] David K.Barton, Sergy A.Leonvov, "Radar Technology Encyclopedia ", Artech house, Boston, London, 1970.

[3] Merrill I.Skolnik, "Radar Hand book", Second Edition, New York, 1972.

[4] Jay, F., IEEE standard dictionary of electrical and electronics term.1995.

[5] Eli Brookner, "Radar Technology", Second Edition, Raytheon Company, Wayland, 1989.

[6] Eugene F.Knott, John F.Shaeffer, Micheal T.Tuley "Radar Cross Section", Second Edition, Artech house, Boston, London, 1994.

[7] J.Clarke,"Advances in Radar Techniques", London, UK, 1985.

[8] J.A.Adam, "How to Design an Invisible Aircraft", IEEE spectrum, vol.25, USA, 1988.

[9] Francois, Lechevalier,"Principles of Radar and Sensor signal processing", Artech house, Boston, London, 2002.

[10] Merrill I.Skolnik, "Introduction to Radar", Third Edition, Mc Graw Hill, New York, 1991.

[11] Juhi Garg, Ashok Gupta "A Guided Tour to K.V Microwave Materials", India, 1991. 